Revista Eletrônica de Direito Processual - REDP.

Rio de Janeiro. Ano 10. Volume 17. Número 2. Julho a Dezembro de 2016

Periódico Semestral da Pós-Graduação Stricto Sensu em Direito Processual da UERJ

Patrono: José Carlos Barbosa Moreira. ISSN 1982-7636. pp. 487-514

www.redp.uerj.br

\title{
LA INTERPRETACIÓN DE LOS DERECHOS FUNDAMENTALES:
}

ALGUNAS REFLEXIONES SOBRE LA TEORÍA DE LA PONDERACIÓN

Y EL PRINCIPIO DE PROPORCIONALIDAD EN LA OBRA DE R.

ALEXY1

INTERPRETATION OF FUNDAMENTAL RIGHTS: SOME THOUGHTS ON

THE THEORY OF WEIGHTS AND THE PRINCIPLE OF PROPORTION IN

THE WORK OF R. ALEXY

Nuria Belloso Martín

Profesora Titular de Filosofía del Derecho (Catedrática Acreditada) Facultad de Derecho, Universidad de Burgos, España. Directora del Departamento de Derecho Público. Coordinadora del Máster en Derecho de la Empresa y de los Negocios. Directora del Curso de Especialista en Mediación Familiar. Directora de Relaciones Internacionales y Cooperación del Grupo de Investigación "Minga. Constitucionalismo democrático latinoamericano, novas intersubjetividades e emancipação social” (Brasil). Investigadora del CES (Universidad de Coimbra).

nubello@ubu.es

RESUMEN: La interpretación de los derechos fundamentales ofrece un rico debate en relación a cuáles pueden ser los mejores criterios para su interpretación. Se analizará la teoría de Robert Alexy en relación a la ponderación. Se analizarán algunas de las críticas y objeciones que se han vertido con respecto a la ponderación y al principio de razonabilidad: si es un procedimiento racional para la aplicación de normas jurídicas o un mero subterfugio retórico, útil para justificar determinadas decisiones judiciales. Ello lleva a otro problema como es el de cómo aplican los Tribunales Constitucionales los principios mediante la ponderación y si tienen legitimidad para ello. Diversos autores han sostenido que la ponderación no es nada más que un juicio arbitrario y salomónico y que, por consiguiente, ni los jueces ni el Tribunal Constitucional tienen la suficiente legitimidad constitucional para aplicar los principios mediante este procedimiento.

\footnotetext{
${ }^{1}$ Artigo recebido em 20/09/2016, sob dispensa de revisão.
} 
Revista Eletrônica de Direito Processual - REDP.

Rio de Janeiro. Ano 10. Volume 17. Número 2. Julho a Dezembro de 2016

Periódico Semestral da Pós-Graduação Stricto Sensu em Direito Processual da UERJ

Patrono: José Carlos Barbosa Moreira. ISSN 1982-7636. pp. 487-514

www.redp.uerj.br

PALABRAS LLAVE: ponderación, principios, razonabilidad, interpretación

\begin{abstract}
The interpretation of fundamental rights offers a rich debate in relation to what may be the best criteria for interpretation. Robert Alexy theory regarding the weighting is analyzed. They discuss some of the criticisms and objections that have been made regarding the weighting and the principle of reasonableness: whether it is a rational procedure for the application of legal rules or a mere rhetorical subterfuge, useful to justify certain judicial decisions. This leads to another problem such as how to apply the principles of constitutional courts by weighting and if they have legitimacy to do so. Several authors have argued that the weighting is nothing more than an arbitrary and Solomonic judgment and that therefore neither the judges nor the Constitutional Court have sufficient constitutional legitimacy to implement the principles by this procedure.
\end{abstract}

KEYWORDS: weight, principles, reasonableness, interpretation

\title{
1. A modo de introducción. Las peculiaridades de la interpretación de los derechos fundamentales
}

La naturaleza y funcionalidad de los derechos fundamentales ha sido objeto de diversas teorías. Entendemos que responden a un potencial emancipador y no opresor. Nuestra posición se inscribe en la perspectiva de interpretación que avala el potencial emancipador de los mismos en la medida en que en un Estado democrático de Derecho debe darse especial relevancia a la interpretación de los derechos fundamentales en clave garantista, ${ }^{2}$ resultado de reivindicaciones a lo largo de la historia. Ello no significa que sea una tarea agotada. Por el contrario, la defensa y garantía de los derechos fundamentales es una tarea in fieri, siempre en continuo proceso de consolidación.

\footnotetext{
${ }^{2}$ Vid. La "esfera de lo indecidible en el constitucionalismo de defensa del concepto de "Ferrajoli (Ferrajoli, L. Democracia y Garantismo, Ed. de M. Carbonell, Trotta, Madrid, 2008; FERRAJOLI, L., Principia juris. Teoria del diritto e della democrazia. Vol. 2: Teoria della democracia, Roma, Laterza, 2007); también, vid, el "coto vedado" (necesidades básicas) de Garzón Valdés (GARZÓN VALDÉS, E., "Algo más acerca del "coto vedado"” en DOXA. Alicante, pp. 209-213. Disponible en: <doxa.ua.es/article/view/1989-n6-algo-mas-acerca-del-coto-vedado/pdf> (Acceso el 28.09.2016).
} 
La dignidad de la persona humana se configura como un principio fundamental general que ilustra la interpretación de los preceptos constitucionales y, más concretamente, de los derechos fundamentales ${ }^{3}$. Si estos diversos derechos fundamentales son, abstractamente, perfectamente compatibles, en el ámbito de lo fáctico pueden presentarse colisiones entre los mismos. El reto ha sido el de buscar un método y sistema que permita privilegiar, circunstancialmente, alguno de los derechos fundamentales en conflicto, pero sin que esto suponga perjudicar otros derechos fundamentales conflictantes en su contenido esencial. La teoría del Profesor Robert Alexy ha aportado elementos de discusión imprescindibles para perfilar una teoría de los derechos fundamentales donde la interpretación, la actividad judicial, ayudados de un proceso de argumentación racional, configuran los principios de proporcionalidad y de razonabilidad ${ }^{4}$.

La aplicación del juicio de proporcionalidad parte del supuesto de que los derechos deben ser realizados en la mayor medida posible, "atendiendo a las posibilidades fácticas y jurídicas que jueguen en sentido contrario" ${ }^{\text {. }}$. Esa verificación de las posibilidades jurídicas que jueguen en sentido contrario se traduce en establecer qué principio se limita con la realización de otro, con el fin de determinar en qué medida se limita éste. La aplicación de este principio implica reconocer que los

\footnotetext{
${ }^{3}$ Con respecto al principio de proporcionalidad, conviene hacer unas precisiones en cuanto a sus posibilidades de aplicación a los derechos fundamentales. Es sólo aplicable a las acciones de los poderes públicos, a diferencia de las acciones entre particulares. Asimismo, este principio es inaplicable cuando entra en escena la dignidad humana, de manera que si un derecho fundamental u otro bien constitucional entran en colisión con la dignidad humana, prevalecerá ésta. En los demás derechos fundamentales, una intromisión no significa todavía una lesión. En cambio, la dignidad humana carece de esa estructura de intromisión/límites. Es decir, tiene carácter de regla, de forma que toda intromisión en la dignidad humana significa su lesión (ALEXY, R., "Entrevista a Robert Alexy", trad. de M. Atienza, DOXA. Revista de Filosofía jurídica,21, Alicante, 2001, pp.670-687).

${ }^{4}$ Entre la amplia producción de Alexy, destacamos ahora cuatro obras que ilustran especialmente el tema que estamos trabajando: ALEXY, R., Tres escritos sobre los derechos fundamentales y la teoría de los principios, Bogotá (Colombia), 2003. En esta obra, reafirma su defensa acerca de los derechos fundamentales, se entenderán estos como principios de optimización que ordenan en su mayoría la relación jurídica fáctica, lo que permitirá entender que no existen derechos absolutos, que es imprescindible su interacción y que la intervención del Estado se legitima mientras se respete el principio de proporcionalidad; ALEXY, R., Teoría de la argumentación jurídica: La teoría del discurso racional como teoría de la fundamentación jurídica, Madrid, Centro de Estudios Políticos y Constitucionales, 2008; ALEXY, R., Teoría de los Derechos fundamentales, Madrid, Centro de Estudios Políticos y Constitucionales, 2008. Y, también, ALEXY, R., A theory of legal argumentation. The theory of rational discourse as theory of legal justification, Oxford, Oxford University Press, 2010. ${ }^{5}$ BERNAL PULIDO, C., El Derecho de los Derechos. Bogotá, Universidad Externado de Colombia, 2005, p.133.
} 
Revista Eletrônica de Direito Processual - REDP.

Rio de Janeiro. Ano 10. Volume 17. Número 2. Julho a Dezembro de 2016

Periódico Semestral da Pós-Graduação Stricto Sensu em Direito Processual da UERJ

Patrono: José Carlos Barbosa Moreira. ISSN 1982-7636. pp. 487-514

www.redp.uerj.br

derechos fundamentales tienen dos contenidos: un contenido prima facie y un contenido definitivo. El contenido prima facie se compone de todas las facultades que pueden adscribirse a los derechos fundamentales cuando son interpretados ampliamente. Este contenido prima facie puede entrar en colisión, como en todo sistema de principios, con otros derechos fundamentales o bienes constitucionales. El contenido definitivo de los derechos fundamentales viene dado por el resultado de la restricción que el legislador -dentro de los márgenes que el principio de proporcionalidad- establezca 6 .

\section{Técnicas de interpretación: la ponderación y sus subprincipios}

Para una adecuada comprensión de las técnicas de interpretación hay que tener presente las tres formas fundamentales de argumentación jurídica: la subsunción, la adecuación (argumentos medio-fin) y la ponderación. A su vez, “cada una de las cuales supone el uso (como premisa) de un enunciado jurídico característico: respectivamente, una regla de acción, una regla de fin y un principio (bien sea un principio en sentido estricto, o bien una directriz)". ${ }^{7}$

Entre las técnicas más utilizadas, principalmente por tribunales latinoamericanos, en Cortes Supremas y Tribunales Constitucionales, están las que derivan de la teoría de $\mathrm{Alexy}^{8}$ que, a su vez, podrían considerarse como una concreción racional del principio de proporcionalidad, característica de los Tribunales Constitucionales europeos.

Para Alexy, una resolución o sentencia emitida por un juez no se refiere únicamente a simples operaciones mecánicas lógicas de subsunción, sino que en los casos difíciles implican valoraciones, sacrificios de principios, una necesidad de ponderación de los valores en conflicto. Alexy considera los derechos constitucionales como principios, y los principios como mandatos de optimización, que ordenan que algo debe realizarse en la mayor medida posible (según las posibilidades fácticas y

\footnotetext{
${ }^{6}$ HERNÁNDEZ DÍAZ, C.A; MAZABEL PINZÓN, M.R., Hermenéutica jurídica e interpretación constitucional, Lima, Ara Editores, 2010, p. 96.

${ }^{7}$ ATIENZA, M., Curso de argumentación jurídica. Madrid, Ed. Trotta, 2013, p.13.

${ }^{8}$ ALEXY, R., Teoría de los derechos fundamentales. Trad. de Carlos Bernal Pulido, Madrid, Centro de Estudios Político Constitucionales, 2008, ( $1^{\mathrm{a}}$ reimp. de la $2^{\mathrm{a}}$ ed.).
} 
Revista Eletrônica de Direito Processual - REDP.

Rio de Janeiro. Ano 10. Volume 17. Número 2. Julho a Dezembro de 2016

Periódico Semestral da Pós-Graduação Stricto Sensu em Direito Processual da UERJ

Patrono: José Carlos Barbosa Moreira. ISSN 1982-7636. pp. 487-514

www.redp.uerj.br

normativas). Cuando se producen conflictos entre derechos (o entre principios), esos

conflictos deben resolverse aplicando un test de proporcionalidad, es decir, aplicando el principio de proporcionalidad que, para Alexy, es una especie de meta-principio.

Alexy esgrime cuatro razones para justificar la necesidad de la ponderación: i) la vaguedad del lenguaje jurídico; ii) la posibilidad de conflictos de normas; iii) el hecho de que sean posibles casos que necesitan una regulación jurídica, pero para cuya regulación no existe ya una norma vigente, y iv) la posibilidad de decidir incluso contra el tenor literal de una norma en casos especiales ${ }^{9}$. Retomando la idea de principios de Dworkin ${ }^{10}$ elabora una teoría de los derechos fundamentales, con el objetivo de construir un esquema argumentativo basado en cuatro elementos fundamentales: la regla, el valor, el principio y la ponderación. Subraya la imposibilidad de dotar de un peso específico a cada derecho fundamental en abstracto, por lo que es necesario su peso concreto a través de la técnica de la ponderación.

La ponderación se encuentra dentro de la proporcionalidad. A su vez, este principio consta de tres sub-principios: el de idoneidad, el de necesidad y el de proporcionalidad en sentido estricto. Así, en cada caso particular donde se aplique la ponderación hay que:

acreditar la adecuación, aptitud o idoneidad de la medida objeto de enjuiciamiento en orden a la protección o

\footnotetext{
${ }^{9}$ ALEXY, R., Teoría de la argumentación jurídica (La teoría del discurso racional como teoría de la fundamentación jurídica). Trad. de Manuel Atienza e Isabel Espejo, Madrid, Centro de Estudios Constitucionales, 1997, p. 23.

${ }^{10}$ Dworkin propone un modelo diferente de función judicial, en relación a los modelos históricos de interpretación judicial, silogístico, realista y discrecional. Es el modelo de la respuesta correcta al problema planteado, dado que sostiene que la verdadera función del juez es hallar la respuesta correcta al caso, hacer justicia. Partiendo de un concepto de interpretación distinto del positivista, subraya que el verdadero problema del Derecho radica en su interpretación y no tanto en su elaboración. Además, como las normas jurídicas tienen un contenido moral, enmarcado en la propia mentalidad socialcolectiva de la comunidad, la interpretación se convierte en un acto jurídico que es inseparable de la moral y sus principios. Una alternativa más sencilla al juez Hercúles omniscente de Dworkin puede ser la idea de una comunidad de intérpretes de la Constitución (H. Hesse, J. Habermas) ${ }^{10}$ de manera que se supera el problema de la dicotomía legitimidad y legalidad de la actuación del Tribunal Constitucional. Vid. BELLOSO MARTÍN, N., "Temi di Teoría Giuridica: L'interpretazione della Costituzione e dei Diritti Fondamentali" en Annali del Seminario Giuridico, Vol. VII (2005-2006), Milano, Giuffrè Editore, 2007, pp.17-85.
} 
Revista Eletrônica de Direito Processual - REDP.

Rio de Janeiro. Ano 10. Volume 17. Número 2. Julho a Dezembro de 2016

Periódico Semestral da Pós-Graduação Stricto Sensu em Direito Processual da UERJ

Patrono: José Carlos Barbosa Moreira. ISSN 1982-7636. pp. 487-514

www.redp.uerj.br

consecución de la finalidad expresada; esto que la actuación afecte a un principio o derecho constitucional ${ }^{11}$.

El principio de proporcionalidad se utiliza para extraer el contenido esencial del derecho fundamental cuya fórmula aparece por primera vez en la Ley Fundamental de Bonn, de 1949, en su artículo 19.2 ${ }^{12}$ y, posteriormente, en la Constitución Española de 1978, en su artículo 53.1 ${ }^{13}$.

A su vez, la estructura de la ponderación, siguiendo a Alexy, consta de tres elementos: la ley de la ponderación, la fórmula del peso y las cargas de la argumentación. La ley de la ponderación se forma así: “cuanto mayor es el grado de la no satisfacción o de afectación de uno de los principios, tanto mayor debe ser la importancia de la satisfacción del otro"; y se concreta a través de tres variables en la fórmula del peso, que son las siguientes: 1) el grado de afectación de los principios en el caso concreto; 2) el peso abstracto de los principios relevantes; 3) la seguridad de las apreciaciones empíricas. Alexy atribuye además un determinado valor numérico a las variables: en cuanto a la afectación de los principios y al peso abstracto, según que la afectación o el peso sea leve, medio o intenso; y en cuanto a la seguridad de las premisas fácticas, según que puedan calificarse de seguras, plausibles o no evidentemente falsas. En aquellos casos en que se produjera un empate (que el peso de los dos principios fuera idéntico), entrarían en juego reglas sobre la carga de la argumentación: por ejemplo, la que establece una prioridad a favor de la libertad, o a favor de la constitucionalidad de una ley (deferencia hacia el legislador) ${ }^{14}$.

La ponderación, según Alexy, es un método para la resolución de cierto tipo de antinomias o contradicciones normativas. A todas aquellas que puedan resolverse

\footnotetext{
${ }^{11}$ ALEXY, R., Teoría de los derechos fundamentales, cit., p. 200.

12 Sobre la restricción de los derechos fundamentales: (2) En ningún caso un derecho fundamental podrá ser afectado en su contenido esencial.

13 Artículo 53.1. "Los derechos y libertades reconocidos en el Capítulo segundo del presente Titulo vinculan a todos los poderes públicos. Sólo por ley, que en todo caso deberá respetar su contenido esencial, podrá regularse el ejercicio de tales derechos y libertades que se tutelarán de acuerdo con lo previsto en el artículo 161,1,a)".

${ }^{14}$ Cfr. ATIENZA, M., “A vueltas con la ponderación”, en Anales de la Cátedra Francisco Suárez. Un panorama de filosofía jurídica y política. 50 años de ACFS. Universidad de Granada, n44, 2010, p.47; También, vid. HERNÁNDEZ MARÍN, R., Interpretación, subsunción y aplicación del Derecho, Marcial Pons, Madrid, 1999.
} 
Revista Eletrônica de Direito Processual - REDP.

Rio de Janeiro. Ano 10. Volume 17. Número 2. Julho a Dezembro de 2016

Periódico Semestral da Pós-Graduação Stricto Sensu em Direito Processual da UERJ

Patrono: José Carlos Barbosa Moreira. ISSN 1982-7636. pp. 487-514

www.redp.uerj.br

mediante alguno de los criterios tradicionales jerárquico, cronológico o de

especialidad no se les aplicará la ponderación ${ }^{15}$. Es evidente que los dos primeros criterios no son aplicables a los conflictos constitucionales, pues se producen en el seno de un mismo documento normativo. No es el caso del tercero: por ejemplo, en la sucesión a la Corona de España se preferirá “el varón a la mujer” (art.57.1 CE) y ésta es una norma especial frente al mandato de igualdad ante la ley del artículo 14, que además prohíbe expresamente discriminación alguna por razón de sexo. Sin embargo, el criterio de especialidad resulta insuficiente para resolver las antinomias de principios. Moreso ha indicado que ello sucede cuando estamos en presencia de derechos (y deberes correlativos) incondicionales y derrotables, es decir, de deberes categóricos o cuya observancia no está sometida a ninguna condición, pero que son prima facie o pueden ser derrotados en algunos $\operatorname{casos}^{16}$.

Es decir, hay supuestos que se caracterizan por la existencia de un conflicto constitucional que no es posible resolver mediante el criterio de la especialidad. Entre el artículo 9.2 y el 14 del texto constitucional español no hay una relación de jerarquía o cronológica ni tampoco de especialidad. Hay que hacer posible la igualdad de todos ante la ley, sin posibilidad de discriminación (art.14) junto con el deber de los poderes públicos promover las condiciones para que la libertad y la igualdad sean efectiva así como de remover los obstáculos que puedan impedirlo (art.9.2). El juez, ante el caso concreto, puede encontrar razones de sentido contradictorio; y no puede resolver el conflicto declarando la invalidez de alguna de esas razones, que son razones constitucionales, ni tampoco afirmando que alguna de ellas ha de ceder siempre en presencia de su opuesta pues esto implicaría establecer una jerarquía que no está en la Constitución. Como ha sostenido el propio Tribunal Constitucional, "no se trata de

\footnotetext{
${ }^{15} \mathrm{El}$ sistema de normas que tenemos, a pesar de su jerarquía, no es perfecto. No resulta posible prever todas las posibles situaciones que puedan presentarse en las complejas relaciones sociales, y el legislador no puede prever esa complejidad de la vida social, por lo que aparecen entonces los conflictos de normas, conocidos como antinomias.

Es el propio sistema el que procura dotarse de criterios para resolver estos conflictos. Para el caso de conflictos de reglas o de normas-disposición, esos criterios de resolución son el cronológico, prevaleciendo la norma posterior a la anterior; el de especialidad, que hace referencia a la especialización de una norma que trata de una determinada materia frente a otra norma de aplicación general, teniendo supremacía aquella sobre ésta; y el criterio de jerarquía, dando primacía a una norma de fuerza mayor en la pirámide jerárquica y suplantando a la norma inferior.

${ }^{16}$ Cfr. MORESO, J.J., "Conflictos entre principios constitucionales”. En Miguel Carbonell Sánchez ( coord. ), Neoconstitucionalismo(s), Madrid, Trotta, 2003: Neoconstitucionalismo(s), cit., pp.99-122. Vid. También, COMANDUCCI, P. "Formas de (neo)constitucionalismo: un análisis metateórico" en Neoconstitucionalismo(s), cit., pp.75-98.
} 
Revista Eletrônica de Direito Processual - REDP.

Rio de Janeiro. Ano 10. Volume 17. Número 2. Julho a Dezembro de 2016

Periódico Semestral da Pós-Graduação Stricto Sensu em Direito Processual da UERJ

Patrono: José Carlos Barbosa Moreira. ISSN 1982-7636. pp. 487-514

www.redp.uerj.br

establecer jerarquías de derechos ni primacías a priori, sino de conjugar, desde la situación jurídica creada, ambos derechos o libertades, ponderando, pesando cada uno de ellos, en su eficacia recíproca" (STC 320/1994).

La ponderación entre principios es una "operación intelectual" que lleva a cabo el juez, y que presenta tres características. En primer lugar, una peculiar interpretación de los principios en juego: sólo cabe en los supuestos de inconsistencia parcial-parcial, según la clasificación de A. Ross, ya que si la antinomia fuese del tipo total-total sería irresoluble, y si fuera del tipo total-parcial bastaría con aplicar el criterio de especialidad; En segundo lugar, el establecimiento de una "jerarquía axiológica" entre los principios en contradicción, esto es, una relación valorativa establecida por el intérprete mediante un juicio de valor; y, en tener lugar, la evaluación del posible impacto del principio que quiere hacerse prevalecer, en su aplicación al caso concreto. En función de estas tres notas, parece que entre dos principios en conflicto se produce una relación jerárquica cambiante según las circunstancias: en un caso se atribuye mayor peso a un principio, y en otro caso distinto, mayor peso a otro principio. La ponderación es una operación que conlleva, por tanto, el establecimiento de una "jerarquía axiológica móvil" que depende, en última instancia y para cada supuesto en concreto, del juicio de valor del intérprete ${ }^{17}$.

Por ello, la ponderación conduce a una exigencia de proporcionalidad que implica establecer un orden de preferencia relativo al caso concreto. Lo característico de la ponderación, como subraya Prieto Sanchís, es que

con ella no se logra una respuesta válida para todo supuesto, no se obtiene, por ejemplo, una conclusión que ordene otorgar preferencia siempre al deber de mantener las promesas sobre el deber de ayudar al prójimo, o a la seguridad pública sobre la libertad individual, sino que se logra una preferencia

${ }^{17}$ Cfr. GUASTINI, R., Distinguendo. Studi di teoria e metateoria del diritto, cit., pp. 142 y ss; o versión en castellano, cit., pp. 167-171; así como "Derecho dúctil, Derecho incierto", en Anuario de Filosofza del Derecho, Tomo XIII, 1996, pp. 121-122; del mismo autor: "Principios de derecho y discrecionalidad judicial", cit., pp. 42-45. 
Revista Eletrônica de Direito Processual - REDP.

Rio de Janeiro. Ano 10. Volume 17. Número 2. Julho a Dezembro de 2016

Periódico Semestral da Pós-Graduação Stricto Sensu em Direito Processual da UERJ

Patrono: José Carlos Barbosa Moreira. ISSN 1982-7636. pp. 487-514

www.redp.uerj.br

relativa al caso concreto que no excluye una solución

diferente en otro caso ${ }^{18}$.

Antes de ponderar es necesario de alguna forma subsumir, mostrar que el caso individual que examinamos forma parte del universo de casos en el que resultan relevantes dos principios en pugna; sin embargo, después de ponderar entendemos que aparece de nuevo la exigencia de subsunción. La ponderación se dirige a formular una regla o una norma en la que, teniendo en cuenta las circunstancias del caso, se elimina o posterga uno de los principios para ceder el paso a otro que, superada la antinomia, opera como una regla $y$, por consiguiente, como la premisa normativa de una subsunción. De ahí también que la ponderación sea una tarea esencialmente judicial ${ }^{19}$.

Progresivamente fueron emergiendo un conjunto de técnicas jurídicas que obligaban a una revisión de las técnicas más consolidadas. Los test de proporcionalidad (costo/beneficio) y de razonabilidad (medios/fines) hacen su entrada con el objetivo de superar el carácter meramente instrumental del silogismo jurídico de razonamiento, facilitando el camino a la "jurisprudencia de valores".

Como hemos puesto de manifiesto, los principios se distinguen de las normas no solamente por el grado de generalidad y abstracción sino también por su alcance y por la función orientadora que desempeñan en el Ordenamiento Jurídico. En este contexto, los principios de razonabilidad y de proporcionalidad se revelan como verdaderos instrumentos para llevar a cabo la ponderación, para la realización de la justicia, abriendo espacio para cuestionarse los actos estatales, como forma de control más eficaz, de modo que se evite, al máximo, la intervención arbitraria del poder público en la esfera de los derechos individuales y colectivos.

a) El principio de proporcionalidad

\footnotetext{
${ }^{18}$ PRIETO SANCHÍS, L., "Neoconstitucionalismo y ponderación judicial", en Anuario de la Facultad de Derecho de la Universidad Autónoma de Madrid, n5, (Ejemplar dedicado a Derecho y proceso) 2001, pp.201-228; también, del mismo autor, vid. "El juicio de ponderación constitucional", en CARBONELL, M., (Editor), El principio de proporcionalidad y la interpretación constitucional, Quito, Ecuador, ministerio de Justicia y Derechos Humanos, 2008, pp.85-124.

${ }^{19}$ Sobre el papel de la ponderación en el neoconstitucionalismo, vid. BELLOSO MARTÍN, Nuria, "El neoconstitucionalismo a debate: entre la principiología y la arbitrariedad", en Revista da Faculdade de Direito da Universidade Federal do Paraná, Curitiba. Brasil, Vol. 59, nº1, 2014, pp.145-178.
} 
Como subraya Carbonell, "El principio de proporcionalidad se vuelve relevante si aceptamos que no existen derechos absolutos, sino que cada derecho se enfrenta a la posibilidad de ser limitado. La cuestión que interesa entonces es de qué manera y con qué requisitos se pueden limitar los derechos" ${ }^{20}$. La resolución de tales conflictos debe de estar sujeta al requisito de "proporcionalidad"21, que Alexy entiende de tres maneras distintas pero complementarias: como adecuación, necesidad y proporcionalidad en sentido estricto. Por tanto, el principio de proporcionalidad está compuesto por tres subprincipios: idoneidad, necesidad y proporcionalidad. El primer subprincipio, el de idoneidad o adecuación, implica que el medio debe ser apto para alcanzar el fin propuesto (fin constitucionalmente justificado), así como que ese medio no impida ni dificulte la realización de otro fin que contemple un principio diferente. Es decir, se trata de dos exigencias, que sea idónea la medida y que sea constitucionalmente permitida. La medida que se adopte para la consecución de los fines propuestos debe ser apropiada y adecuada, para la consecución del interés público. Se trata de controlar la adecuación de la relación entre la medida y el fin. Este control viene siendo muy debatido por la doctrina y por la jurisprudencia en relación al poder discrecional de la Administración pública.

El segundo subprincipio, el de necesidad, implica considerar las alternativas menos invasivas de los derechos fundamentales, pues si existen otros medios que permitan lograr el mismo fin perseguido con una menor restricción o limitación del derecho fundamental, la medida debe ser declarada inconstitucional por ser innecesaria. Por necesidad cabe entender que el medio empleado no se puede considerar apto si existe otro medio alternativo igualmente idóneo para la consecución del fin, y menos gravoso para el fin exigido por otro principio. Intenta proteger el derecho a que el

${ }^{20}$ CARBONELL, M., "Introducción. El principio de proporcionalidad y los derechos fundamentales" en CARBONELL, M., (Editor), El principio de proporcionalidad y la interpretación constitucional, Quito, Ecuador, ministerio de Justicia y Derechos Humanos, 2008, p.10.

21 GUERRA FILHO, W. S., "Sobre os princípios constitucionais gerais: isonomia e proporcionalidade". En: Revista dos Tribunais, n719, Sâo Paolo, sept.1995; también, del mismo autor, $O$ princípio da proporcionalidade na Constituição. Rio de Janeiro. Disponible en: <http: //www.teiajuridica.com>. Cabe afirmar que los principios de proporcionalidad y de razonabilidad pueden encontrarse en la Constitución de Brasil de 1988, aunque sea de forma implícita. La razonabilidad se encuentra en el requisito del "debido proceso legal", garantía contemplada en el artículo $5^{\circ}$, LVI, y la proporcionalidad deriva de la interpretación de los principios concretizadores del Estado de Democrático de Derecho, como elemento inspirador de la Carta Magna brasileña. 
Revista Eletrônica de Direito Processual - REDP.

Rio de Janeiro. Ano 10. Volume 17. Número 2. Julho a Dezembro de 2016

Periódico Semestral da Pós-Graduação Stricto Sensu em Direito Processual da UERJ

Patrono: José Carlos Barbosa Moreira. ISSN 1982-7636. pp. 487-514

www.redp.uerj.br

ciudadano tenga la menor desventaja posible. Esto requiere la prueba de que, para la obtención de determinados fines, resultaba imposible adoptar un medio menos oneroso para el ciudadano. La doctrina apunta cuatro elementos para facilitar la aplicación práctica del principio: la exigibilidad material, que impone la menor limitación de los derechos fundamentales; la exigibilidad espacial, que hace referencia a la limitación del ámbito de intervención; la exigibilidad temporal, que presupone una rigurosa delimitación del tiempo de la medida coactiva por parte del poder público, y, finalmente, la exigibilidad personal, que impone la limitación de la medida a las personas cuyos intereses deban ser sacrificados. ${ }^{22}$ El principio de necesidad conlleva comprobar si el legislador podría haber adoptado otro medio igualmente eficaz y más ventajoso para los ciudadanos. El tercer subprincipio, el de proporcionalidad en sentido estricto, significa que en la aplicación de un principio hay que tener en cuenta las exigencias de los principios contrapuestos en función de las circunstancias del caso $^{23}$. Es decir, para que una medida restrictiva de derechos fundamentales sea legítima, el grado del objetivo de la intervención debe ser equivalente al grado de afectación de la libertad o del derecho fundamental ${ }^{24}$.

En Alemania y en Suiza prevalece la perspectiva doctrinal y jurisprudencial según la cual el principio de proporcionalidad es un principio general del Derecho Constitucional, junto al principio de Estado de Derecho. Los constitucionalistas afirman que el instituto es de la misma naturaleza que los derechos fundamentales ${ }^{25}$. Entretanto, parte de la doctrina más moderna ya afirmaba que se trataba de un principio general del Derecho. Alexy destaca el vínculo entre la proporcionalidad y la teoría de los principios, afirmando que el carácter de principio implica el de proporcionalidad y viceversa:

Que el carácter de principio que implica el principio de proporcionalidad significa que el principio de proporcionalidad con sus tres principios parciales de

\footnotetext{
${ }^{22}$ SLAIB FILHO, N., Breve historia do controle de constitucionalidade. Rio de Janeiro, Disponible en <http: //www.nagib.net.> (www.tjrj.jus.br/c/document.../get_file?uuid). (Acceso el 28.09.2016).

23 Cfr. ALEXY, R., Teoría de los derechos fundamentales, cit., pp. 100 y ss. Respecto a la jurisprudencia constitucional española, puede verse la STC 66/1995, entre otras.

24 Sobre la problemática de la discrecionalidad técnica, vid. IGARTUA SALAVERRÍA, J., Discrecionalidad técnica, motivación y control jurisdiccional. Madrid, Civitas, S.A., 1998.

25 BONAVIDES, P., Curso de Direito Constitucional. $4^{\mathrm{a}}$ ed., São Paulo, Malheiros, 1994, p.401.
} 
Revista Eletrônica de Direito Processual - REDP.

Rio de Janeiro. Ano 10. Volume 17. Número 2. Julho a Dezembro de 2016

Periódico Semestral da Pós-Graduação Stricto Sensu em Direito Processual da UERJ

Patrono: José Carlos Barbosa Moreira. ISSN 1982-7636. pp. 487-514

www.redp.uerj.br

pertinencia, necesidad o mandato de uso del medio más

blando, y proporcionalidad en sentido estricto, además, mandato de ponderación o valoración, lógicamente resulta de la naturaleza de principio, a saber, se deduce de este.

La relevancia que adquiere el principio de proporcionalidad deriva no sólo porque permite dirimir conflictos que se presenten en una misma ley de carácter infraconstitucional, sino porque permite hacer la ponderación o sopesamiento de principios y derechos fundamentales, así como de los intereses y bienes jurídicos en que se expresen, cuando se encuentren en una situación de contradicción, solucionándolo de forma que maximice el respeto a todos los que se encuentren implicados en el conflicto ${ }^{26}$.

Por tanto, los jueces y magistrados deben preguntarse en primer lugar cuál es la importancia del fin perseguido con la medida y, si esa intervención está permitida por la Constitución. Seguidamente, deben entrar a verificar si no existe un medio más idóneo que permita lograr el mismo fin perseguido, con una menor restricción o limitación del derecho fundamental. Después, se preguntará cuál es la importancia del derecho fundamental que se limita mediante la ley. Finalmente, una vez comparados los dos derechos en conflicto y habiendo determinado que el que se limita se hace en la misma medida en que se realiza el otro, se debe comprobar que esa medida adoptada por el legislador se adapta a la Constitución.

Fernández Segado nos trae un interesante ejemplo que podría traerse a colación viene dado por la Sentencia 113/198927, por el que el Tribunal Constitucional se pronuncia sobre la cuestión de inconstitucionalidad promovida por la Sección Primera de la Audiencia Provincial de Oviedo, respecto del Art. 22 del Texto Refundido de la Ley General de la Seguridad Social. La cuestión se planteaba porque la ejecución de una

${ }^{26}$ Vid. CLÉRICO, L., El examen de proporcionalidad en el Derecho constitucional. Buenos Aires, Eudeba, 2009.

${ }^{27}$ Esta Sentencia es citada por Fernández Segado, no para explicar el principio de proporcionalidad sino el tipo de sentencias manipulativas: "El Juez constitucional español ha dictado algunas decisiones reconducibles, a nuestro juicio, a la genérica categoría de las sentencias manipulativas, en las que esa «manipulación»se opera a través de la reducción del contenido dado por el legislador a una determinada disposición, que, sin ser anulada, ve reformulado en un sentido reductor su contenido" (FERNÁNDEZ SEGADO, M., "El Tribunal Constitucional español como legislador positivo" en Pensamiento Constitucional Año XV N 15, p.183). 
Revista Eletrônica de Direito Processual - REDP.

Rio de Janeiro. Ano 10. Volume 17. Número 2. Julho a Dezembro de 2016

Periódico Semestral da Pós-Graduação Stricto Sensu em Direito Processual da UERJ

Patrono: José Carlos Barbosa Moreira. ISSN 1982-7636. pp. 487-514

www.redp.uerj.br

sentencia, en la que se había condenado al autor de un delito de lesiones graves a abonar una indemnización que se venía satisfaciendo a través de una retención mensual de parte del salario del condenado, se vio interrumpida desde que este causó baja en el trabajo y pasó a percibir una prestación económica de la Seguridad Social, siendo, precisamente, la inembargabilidad de estas prestaciones, establecida en el Art. 22.1 de la mencionada Ley, lo que provocó la declaración de insolvencia del condenado y la consiguiente interrupción del abono de la indemnización. El Juez constitucional recuerda que entre las variadas razones que motivan las declaraciones legales de inembargabilidad destaca la social de impedir que la ejecución forzosa destruya por completo la vida económica del ejecutado y se ponga en peligro su subsistencia personal y la de su familia y, a tal fin, la ley establece normas de inembargabilidad de salarios y pensiones que son, en muchas ocasiones, la única fuente de ingresos de gran número de ciudadanos. Sin embargo, comprobada la justificación constitucional de la inembargabilidad de bienes y derechos como límite del derecho a ejecutar sentencias firmes, el Tribunal se centra en el examen de si la inembargabilidad establecida en la norma legal cuestionada cumple la regla de proporcionalidad de los sacrificios, de obligada observancia en toda limitación de un derecho fundamental ${ }^{28}$.

Entiende el Tribunal que «para que dicha proporcionalidad se cumpla es preciso que la declaración legal de inembargabilidad se desenvuelva dentro de los límites cuantitativos que resulten imprescindibles para asegurar el mínimo económico vital de sus beneficiarios y no los sobrepasen de manera tal que se extienda su inmunidad frente a la acción ejecutiva de los acreedores en cuantía que resulte excedente a ese mínimo vital, pues en este caso se estará sacrificando el derecho fundamental de los acreedores a hacer efectivo el crédito judicialmente reconocido más allá de lo que exige la protección de los valores constitucionales que legitima la limitación de este derecho». A partir de este razonamiento, el Tribunal declara inconstitucional el precepto impugnado «en la medida en que, al no señalar límite cuantitativo, constituye (un) sacrificio desproporcionado del derecho a que las sentencias firmes se ejecuten, garantizado [...] por el Art. 24.1 de la Constitución». En definitiva, el precepto cuestionado sería inconstitucional no por establecer la

${ }^{28}$ STC 113/1989, de 22 de junio, fund. jur. 3. 
Revista Eletrônica de Direito Processual - REDP.

Rio de Janeiro. Ano 10. Volume 17. Número 2. Julho a Dezembro de 2016

Periódico Semestral da Pós-Graduação Stricto Sensu em Direito Processual da UERJ

Patrono: José Carlos Barbosa Moreira. ISSN 1982-7636. pp. 487-514

www.redp.uerj.br

inembargabilidad de las prestaciones de la Seguridad Social, sino por hacerlo de manera incondicionada y al margen de su cuantía, pronunciamiento que aun no siendo en sentido estricto sustitutivo, sí viene a entrañar una cierta sustitución de la voluntad expresada por el legislador en cuanto que el Tribunal entiende que el Art. 22.1, disposición perteneciente a una ley preconstitucional, bien podría ser considerado derogado por otras normas, como el Art. 1.449 de la Ley de Enjuiciamiento Civil, que reduce la inembargabilidad de las pensiones a la cuantía señalada para el salario mínimo interprofesional, y así lo podría haber constatado el juez a quo. Ello, de facto, vendría a suponer la sustitución de una norma por otra, ambas, ciertamente, emanadas del propio legislador ${ }^{29}$.

b) El principio de razonabilidad

Un criterio a tener en cuenta, junto a la proporcionalidad, es el de la razonabilidad, que cada vez cuenta con mayor presencia e importancia en la jurisprudencia, especialmente en la constitucional, y no sólo en la española ${ }^{30}$. A pesar de que tal criterio puede llegar a ser confundido con el de proporcionalidad en sentido estricto, lo cierto es que puede dar lugar a un juego argumentativo mucho mayor que este último. El recurso a "lo razonable" permite al juez buscar el equilibrio entre principios o derechos desde parámetros próximos a la idea de consenso social. La razonabilidad no es un concepto claramente delimitado, sino una "noción de contenido variable" que abarca un campo de acción y aplicación muy amplio.

La razonabilidad como concepto procedimental puede delimitarse a partir de tres requisitos: i) sólo sería aceptable en situaciones que necesiten sobrepasar los mecanismos de la racionalidad formal; ii) con ella se intenta lograr un equilibrio óptimo entre las diferentes exigencias en conflicto; iii) debe obtenerse, a su vez, y a través de ella, el máximo de consenso social, esto es, debe ser aceptada por la comunidad. Consiste en apelar a un "espíritu de adaptación" para resolver los

\footnotetext{
${ }^{29}$ FERNÁNDEZ SEGADO, M., "El Tribunal Constitucional español como legislador positivo" en Pensamiento Constitucional Año XV N 15, p. 184.

${ }^{30} \mathrm{El}$ test de razonabilidad se ha convertido en un recurso interpretativo básico en materia de derechos fundamentales, tanto en la jurisprudencia norteamericana como en la europea. Al respecto, véase el estudio comparado de ALONSO GARCIA, E., La interpretación de la Constitución, Centro de Estudios Constitucionales, Madrid, 1984.
} 
Revista Eletrônica de Direito Processual - REDP.

Rio de Janeiro. Ano 10. Volume 17. Número 2. Julho a Dezembro de 2016

Periódico Semestral da Pós-Graduação Stricto Sensu em Direito Processual da UERJ

Patrono: José Carlos Barbosa Moreira. ISSN 1982-7636. pp. 487-514

www.redp.uerj.br

conflictos mediante la adopción de soluciones que satisfagan a todos en el mayor

grado posible; por ello, debería ser más que un argumento subjetivo del jurista, un requisito objetivo del Derecho ${ }^{31}$.

Pretender que las decisiones judiciales estén siempre "razonadas", no oculta algunos de los problemas, límites e inconvenientes que tiene la propia noción de razonabilidad en su aplicación al Derecho ${ }^{32}$. Resulta intrínseco a la misma su carácter vago, impreciso y variable, aunque también cabría decir que este defecto congénito puede convertirse en una cierta ventaja, por su carácter de concepto jurídico indeterminado. Esto quiere decir que su alto nivel de indeterminación, tanto en sentido espacial como temporal, permitiría incluso afirmar que dos o más soluciones para un mismo caso, en principio diferentes, pueden ser al mismo tiempo razonables; por lo tanto, más bien se trata de justificar cuál de ellas es "más razonable" que la otra, aportando argumentos. Al menos, de esta forma se obliga al juez a justificar su decisión, lo cual ya es un logro.

El principio de razonabilidad tuvo inicialmente su aplicación en el Derecho Administrativo, aplacando la fuerza del Estado en relación a sus jurisdiccionados. Posteriormente fue elevado a categoría de principio constitucional en diversos países $\mathrm{y}$, finalmente, se fue extendiendo, con mayor o menor intensidad, a una buena parte de los países democráticos. La evolución del principio de razonabilidad se confunde con la propia evolución del "debido proceso legal". El instituto, considerado como un desdoblamiento de la cláusula, sirve como parámetro para limitar el arbitrio del Estado en sus diversas relaciones con el individuo y con la sociedad, por medio de su utilización como criterio de interpretación de las leyes. Los jueces de la Suprema

31 Cfr. ATIENZA, M., "Para una razonable definición de 'razonable"', Doxa. Cuadernos de Filosofía del Derecho, núm. 4, Alicante, 1987, pp. 189 y ss; también, del mismo autor, Tras la justicia. Una introducción al Derecho y al razonamiento jurídico, Ariel, Barcelona, 1993, p. 175.

${ }^{32}$ El propio Tribunal Constitucional español ha dicho que "la razonabilidad no es un puro sinónimo de corrección hermenéutica, sino también, además de ello, exigencia de adecuación a los valores que la Constitución incorpora" (STC 261/1989, de 16 de octubre, f.j. $4^{\circ}$ ). Mediante la razonabilidad, a fin de cuentas, se trata de buscar un equilibrio entre valores y principios constitucionales y las razones alegadas en un conflicto. Sobre ello, y respecto a su aplicación concreta por el Tribunal Constitucional español a supuestos de objeción de conciencia u otros, véase DE LUCAS, J; VIDAL, E., "Una nota sobre interpretación constitucional en materia de derechos fundamentales", en VV.AA., Diez años de régimen constitucional (E. Álvarez Conde, ed.), Tecnos, Madrid. 1989, pp. 15 y ss.; así como "Razonabilidad e interpretación constitucional: a propósito de una jurisprudencia reciente", en Introducción a los derechos fundamentales, vol. III, Servicio de Publicaciones del Ministerio de Justicia, Madrid, 1989. 
Revista Eletrônica de Direito Processual - REDP.

Rio de Janeiro. Ano 10. Volume 17. Número 2. Julho a Dezembro de 2016

Periódico Semestral da Pós-Graduação Stricto Sensu em Direito Processual da UERJ

Patrono: José Carlos Barbosa Moreira. ISSN 1982-7636. pp. 487-514

www.redp.uerj.br

Corte norteamericana adoptaron la razonabilidad como criterio hermenéutico, para

combatir las intervenciones del Estado en los derechos fundamentales, a partir de la teoría del substantive due process of law. Fue una reacción del Poder Judicial al paquete de medidas adoptadas por el Presidente Roosevelt, el New Deal, a partir de la década de los años treinta. A partir de ahí, la razonabilidad empezó a tener el carácter de postulado genérico de legalidad y a exigir que los actos del poder público fueran compatibles con la noción de un derecho justo ${ }^{33}$.

La razonabilidad es adoptada en conjunto con otros principios constitucionales, como por ejemplo, el principio da isonomía ${ }^{34}$, protegiendo al ciudadano contra todo acto del Poder Público que se revele arbitrario. En este campo de actuación, desempeña un papel semejante al desarrollado por la teoría francesa de desvío de poder. La finalidad no es la de demostrar que el legislador estableció diferencias entre los ciudadanos sino que lo hizo de forma irrazonable, atentando injustificadamente contra la garantía constitucional.

Según la doctrina y jurisprudencia norteamericana, una norma es irrazonable y, por tanto, está sometida al examen del Poder Judicial cuando adopta como criterio un hecho de la naturaleza independiente de la voluntad humana, como sexo, raza, nacionalidad y filiación, para diferenciar situaciones jurídicas, o cuando interfiere en los derechos fundamentales reconocidos, de modo implícito o explícito, por la Constitución. Tales normas tiene presunción relativa de inconstitucionalidad que puede ser contrarrestada mediante la demostración inequívoca de que la regla está en conformidad con el interés público, y es imposible atenderlo por otro medio. Para combatir el arbitrio del Estado con fundamento en la razonabilidad es necesario el examen de la compatibilidad entre el fin cuya consecución se pretende y el medio escogido para alcanzarlo. En este sentido, la razonabilidad de los norteamericanos se identifica con la proporcionalidad en sentido estricto del sistema alemán. ${ }^{35}$

En el contexto brasileño, algunos autores sitúan el principio da razonabilidad

\footnotetext{
${ }^{33}$ Vid. SIQUEIRA CASTRO, C. R. de, O devido processo legal e a razoabilidade das leis na nova Constituição do Brasil. Rio de Janeiro, Forense, 1989.

${ }^{34}$ Vid. GUERRA FILHO, Willis Santiago, "Sobre os princípios constitucionais gerais: isonomia e proporcionalidade", en Revista dos Tribunais, n719, sept., Sâo Paolo, 1995.

35 Esto explica porqué algunos autores consideran ambos institutos como sinónimos.
} 
Revista Eletrônica de Direito Processual - REDP.

Rio de Janeiro. Ano 10. Volume 17. Número 2. Julho a Dezembro de 2016

Periódico Semestral da Pós-Graduação Stricto Sensu em Direito Processual da UERJ

Patrono: José Carlos Barbosa Moreira. ISSN 1982-7636. pp. 487-514

www.redp.uerj.br

como sinónimo del principio de proporcionalidad, además de que algunos otros autores los clasifican como criterios hermenéuticos. Barroso los sitúa entre los principios de interpretación específicamente constitucional:

A doutrina e a jurisprudência, assim na Europa continental como no Brasil, costumam fazer referência, igualmente, ao princípio da proporcionalidade, conceito que em linhas gerais mantém um relação de fungibilidade com o princípio da razoabilidade. Salvo onde assinalado, um e outro serão aqui empregados indistintamente. ${ }^{36}$

Asimismo, hay algunos autores que no comparten la fungibilidad entre los institutos, como Slaib Filho, que entiende que se trata, en realidad, de un subprincipio del instituto de proporcionalidad ${ }^{37}$. También, Aziz Cretton defiende la razonabilidad como separado de la proporcionalidad, teniendo el cuidado de delinear las características de cada instituto. Además, considera los institutos como de la misma naturaleza jurídica, es decir, como principio general del derecho, acompañando a la doctrina más moderna, tanto la norteamericana como la europea. ${ }^{38}$

Por nuestra parte, también distinguimos entre el principio de proporcionalidad y el de razonabilidad. La razonabilidad es más un principio de carácter negativo, capaz solamente de poner de manifiesto que, por ejemplo, un determinado acto administrativo, no cumple su finalidad, por absurdo o arbitrario. En cambio, el principio de proporcionalidad se vincula principalmente a la racionalidad o racionalización de los actos más que a una simple razonabilidad. El principio de proporcionalidad funciona como un mandato de optimización de respeto máximo a

36 BARROSO, L. R.; BARCELlOS; A.P. (de), "O começo da historia. A Nova Interpretação Constitucional e o Papel dos Princípios no Direito Brasileiro" en Revista da EMERJ, v. 6, n. 23, 2003 , p. 125. Disponible en. <www.emerj.tjrj.jus.br/revistaemerj_online/.../revista23_25.pdf >. (Acceso el 28.09.2016).

Barroso defiende la aplicabilidad del instituto bajo dos aspectos: la razonabilidad interna, que hace referencia a la relación "racional y proporcional" entre motivos, medios y fines, refriéndose a lo que denomina "razoabilidade técnica da medida" y, la "razoabilidade externa", cuya verificación corresponde a la adecuación a los medios y fines admitidos y preconizados por el texto Constitucional (op.cit., p.217).

${ }^{37}$ SLAIBI FILHO, N., "Hermenêutica Constitucional", Revista da EMERJ, nº 16. Rio de Janeiro, 2001.

38 AZIZ CRETTON, R., Os princípios da proporcionalidade e da razoabilidade e sua aplicação no Direito Tributário. Rio de Janeiro, Lumen Iuris, 2001, p. 75. 
Revista Eletrônica de Direito Processual - REDP.

Rio de Janeiro. Ano 10. Volume 17. Número 2. Julho a Dezembro de 2016

Periódico Semestral da Pós-Graduação Stricto Sensu em Direito Processual da UERJ

Patrono: José Carlos Barbosa Moreira. ISSN 1982-7636. pp. 487-514

www.redp.uerj.br

todo derecho fundamental ${ }^{39}$. El concepto de proporcionalidad se encuentra todavía en

evolución, dada la naturaleza flexible del instituto. La violación del principio se viene considerando grave, al menos en los países cuyo sistema hermenéutico se funda en la teoría material de la Constitución.

\section{Algunas objeciones a la teoría de la ponderación y al principio de proporcionalidad de Alexy}

Siguiendo la teoría de Alexy, hay numerosos defensores de la ponderación y, concretamente, del principio de proporcionalidad. La vaguedad e indeterminación de las normas de Derecho constitucional y su derrotabilidad en el plano de la jurisdicción constitucional en los casos difíciles, exige un ejercicio hermenéutico complejo de individualización a partir de las limitaciones externas a los principios que se encuentran en conflicto ${ }^{40}$. Sin embargo, también se han formulado objeciones. Como advierte Bernal Pulido, uno de los problemas más frecuentes es si la ponderación es un procedimiento racional para la aplicación de normas jurídicas o un mero subterfugio retórico, útil para justificar determinadas decisiones judiciales. Este es un interrogante filosófico jurídico que, sin embargo, irradia sus efectos sobre un segundo problema, relevante desde el punto de vista del derecho constitucional. Ese segundo problema se refiere a la legitimidad del juez, y en especial del Tribunal Constitucional, para aplicar los principios mediante la ponderación. Diversos autores han sostenido que la ponderación no es nada más que un juicio arbitrario y salomónico ${ }^{41}$ y que, por

\footnotetext{
${ }^{39}$ En este mismo sentido se ha manifestado GUERRA FILHO, W.S., Processo Constitucional e Direitos Fundamentais. Instituto Brasilero de Direito Constitucional, Cesar Bastos Editor, 1999; también, del mismo autor, vid. Teoría Processual da Constituiçâo. $2^{\mathrm{a}}$ ed., Sâo Paolo, Instituto Brasilero de Direito Constitucional, 2002.
}

${ }^{40}$ LÓPEZ SÁNCHEZ, R., "El principio de proporcionalidad como criterio hermenéutico en la justicia constitucional”, en Cuadernos Electrónicos de Filosofía del Derecho, n.23, 2011, p. 322.

${ }^{41}$ Lo que busca la ponderación es la norma adecuada al caso, y no, como parece sugerir Habermas, la imposición más o menos arbitraria de un punto medio; no se trata de negociar entre valores de un modo particularista, sino de construir una regla susceptible de universalización para todos los casos que presenten análogas propiedades relevantes (HABERMAS, J., Facticidad y Validez. Sobre el derecho y el Estado democrático de derecho en términos de teoría del discurso. Trad. de Manuel Jiménez Redondo, Madrid, Trotta 1998, p. 327 s); también se muestra crítico Jiménez Campo, concretamente con relación a la inconveniencia de la ponderación en los procesos sobre la constitucionalidad de la ley. Jiménez Campo, que no tiene "ninguna duda sobre la pertinencia del control de proporcionalidad en la interpretación y aplicación judicial de los derechos fundamentales "pero no así en cuanto a que por su alto grado de indeterminación, termina siendo el Tribunal Constitucional quien tiene la última 
Revista Eletrônica de Direito Processual - REDP.

Rio de Janeiro. Ano 10. Volume 17. Número 2. Julho a Dezembro de 2016

Periódico Semestral da Pós-Graduação Stricto Sensu em Direito Processual da UERJ

Patrono: José Carlos Barbosa Moreira. ISSN 1982-7636. pp. 487-514

www.redp.uerj.br

consiguiente, ni los jueces ni el Tribunal Constitucional tienen la suficiente legitimidad constitucional para aplicar los principios mediante este procedimiento. Si lo hacen, estarán restringiendo o, incluso usurpando funciones y competencias que no les corresponden, y que la Constitución las ha atribuido a otros poderes el Estado ${ }^{42}$.

Si bien la ponderación, desde su estructuración por Alexy goza de numerosos defensores, también hay escépticos con respecto a la misma. Así, algunos autores sostienen que la técnica de la ponderación no puede considerarse como la interpretación más adecuada para un conflicto entre normas y/o reglas que afectan a derechos fundamentales. En este sentido, Guastini ha subrayado que, además de establecer una jerarquía axiológica movediza, puesto que es variable en la solución de casos, el conflicto no queda resuelto de manera estable: la ponderación es un procedimiento de resultados imprevisibles, que fomenta la "jerarquía axiológica movediza" y que no permite una solución "fija" del mismo conflicto ${ }^{43}$.

García Amado duda de la racionalidad de la ponderación en cuanto tal, porque considera que la ponderación no es otra cosa que una valoración y se confiesa escéptico con respecto a la existencia de criterios objetivos de valoración. Es decir, considera que la ponderación cumple una función esencialmente ideológica:

Y por eso también [además de los neoconstitucionalistas] es esta de la ponderación la doctrina que con más entusiasmo acogen los propios tribunales Constitucionales, pues es la única que aún hoy puede dotar de apariencia de objetividad a sus decisiones y, de paso, justificar el creciente y universal activismo y casuismo de los tales Tribunales, siempre en detrimento del legislador ${ }^{44}$.

palabra sobre todos los asuntos (JIMÉNEZ CAMPO, J., Derechos Fundamentales. Concepto y garantías, Madrid, Trotta, 1999, p. 73).

42 BERNAL PULIDO, C., "La racionalidad de la ponderación”, en CARBONELL, M., (Editor), El principio de proporcionalidad y la interpretación constitucional, Quito, Ecuador, Ministerio de Justicia y Derechos Humanos, 2008, p.44.

43 Citado en: MARTÍNEZ ZORRILLA, D., Conflictos constitucionales, ponderación e indeterminación normativa, Madrid, Marcial Pons, 2007, p. 161.

${ }^{44}$ GARCÍA AMADO, J. A., "El juicio de ponderación y sus partes. Una crítica” en ALEXY, R., "Derechos sociales y ponderación", GARCÍA MANRIQUE, Ricardo (ed.), Madrid, Fundación Coloquio Jurídico Europeo, 2007. Citamos por: GARCÍA AMADO, J.A., GARCÍA AMADO, J.A., El 
Y en cuanto a lo que la ponderación pueda ofrecer de novedoso, García Amado, sostiene que

[...] la ponderación (Abwägung), como método, no tiene autonomía, pues su resultado depende de la interpretación de las normas constitucionales y/o legales que vengan al caso. Cuando los Tribunales Constitucionales dicen que ponderan siguen aplicando el tradicional método interpretativo/subsuntivo, pero cambiando en parte la terminología y con menor rigor argumentativo, pues dejan de argumentar sobre lo que verdaderamente guía sus decisiones: las razones y valoraciones que determinan sus elecciones interpretativas ${ }^{45}$.

García Amado subraya que si lo anterior es cierto, implica que no hay diferencias cualitativas y metodológicamente relevantes entre: i) Reglas y principios; ii) Decisiones de casos constitucionales y casos de legislación ordinaria. Todo esto implica que todo caso, tanto de legalidad ordinaria como constitucional, puede ser presentado, decidido y fundamentado como caso de conflicto entre principios (incluso constitucionales) o de subsunción bajo reglas. Es decir, si la ponderación (balanceo entre principios) se aplica sin el debido rigor, podríamos evolucionar a: (i) que todo caso de legalidad ordinaria puede ser transformado en caso de conflicto entre principios y (ii) que todo caso de los que deciden los Tribunales Constitucionales puede reconducirse a un problema de subsunción de hechos bajo (la referencia de) enunciados, con la necesaria mediación, por tanto, de la actividad interpretativa, es decir, de decisiones de atribución de significado (de entre los significados posibles).

García Amado, examina el principio de proporcionalidad (Verhältnismässigkeitsgrundsatz), con sus tres subprincipios, idoneidad, necesidad y

juicio de ponderación y sus partes. Crítica de su escasa relevancia, p.1. www.geocities.ws/jagamado/pdfs/PONDERACION.pdf (acceso el 23.02.2014), p.4, nota.

${ }^{45}$ GARCÍA AMADO, J.A., El juicio de ponderación y sus partes. Crítica de su escasa relevancia, cit., p.1. www.geocities.ws/jagamado/pdfs/PONDERACION.pdf (acceso el 23.02.2014). 
Revista Eletrônica de Direito Processual - REDP.

Rio de Janeiro. Ano 10. Volume 17. Número 2. Julho a Dezembro de 2016

Periódico Semestral da Pós-Graduação Stricto Sensu em Direito Processual da UERJ

Patrono: José Carlos Barbosa Moreira. ISSN 1982-7636. pp. 487-514

www.redp.uerj.br

proporcionalidad en sentido estricto (Geeignigkeit, Erforderlichkeit,

Verhältnismässigkeit im engeren Sinne), a partir de tres sentencias que cita como ejemplo el propio Alexy en su Epílogo ${ }^{46}$. Con el análisis detallado del razonamiento contenido en esas sentencias trata de poner de relieve que:

[...] dichos tres principios carecen de autonomía operativa y son, al menos en cierto sentido, triviales o prescindibles, pues las magnitudes sobre las que se aplican (lo que se "pesa") o el resultado de su aplicación (el "peso" resultante) está decisivamente condicionado por las interpretaciones previas que de las normas que vengan al caso haya hecho el Tribunal, $\mathrm{y}$, con ello, por las contingentes valoraciones o preferencias del Tribunal. En otras palabras, un tanto simplificadoras: es la conciencia valorativa del Tribunal, su ideología, lo que determina tanto qué es lo que en concreto se ha de pesar, de poner en cada platillo de la balanza, como el resultado de ese pesaje o ponderación ${ }^{47}$.

Así, con respecto al subprincipio de idoneidad señala sólo opera, y opera bien, cuando se ha predecidido entre qué dos derechos o principios tiene lugar el conflicto que en el caso se dirime. Y es tal predecisión la que predetermina el resultado final de la aplicación del principio de idoneidad. Pero esa predecisión es una opción valorativa que toma el intérprete, el Tribunal en este caso, no algo que se siga casi nunca con plena evidencia y de modo indiscutible. "En los casos de ponderación lo decisivo es la interpretación previa de las normas concurrentes y que la operación ponderativa es sólo el tramo final y más irrelevante".

Por su parte, Moreso también es escéptico en cuanto a la racionalidad de la ponderación tal y como la entiende Alexy ya que considera que incurre en particularismo, es decir, que no pasaría el test de la universalidad ni, en consecuencia, todos los demás criterios de la racionalidad práctica. En la concepción

${ }^{46}$ ALEXY, R.," Epílogo a la Teoría de los derechos fundamentales", trad. de C. Bernal, Revista Española de Derecho Constitucional, 22, nº. 66, 2002.

${ }^{47}$ Ibidem. 
Revista Eletrônica de Direito Processual - REDP.

Rio de Janeiro. Ano 10. Volume 17. Número 2. Julho a Dezembro de 2016

Periódico Semestral da Pós-Graduação Stricto Sensu em Direito Processual da UERJ

Patrono: José Carlos Barbosa Moreira. ISSN 1982-7636. pp. 487-514

www.redp.uerj.br

de Alexy, los principios ordenan maximizar, en el mayor grado posible, estados de cosas que juzgamos valiosos. A este respecto, Moreso apunta tres dudas: La primera duda es la siguiente: dado que los pesos abstractos de los principios son independientes de cualquier circunstancia concreta, deberíamos tener a nuestra disposición una asignación de peso abstracto para cada principio que establece un derecho constitucional, deberíamos tener una escala de ordenación abstracta de los derechos. No conozco ninguna escala de este tipo que pueda ser aceptada razonablemente [...]. La segunda duda guarda relación con la distinción de Alexy entre interferencias leves, moderadas y graves en los principios constitucionales. “Aquí estamos frente a una escala, pero ¿de qué depende la asignación de estos tres conceptos en un caso concreto?" [...] La tercera y última duda está relacionada con la insistencia de Alexy en que la operación de ponderación se refiere siempre a un caso individual $^{48}$.

Como acertadamente subraya Prieto Sanchís, se ha criticado que:

[...] la máxima de la ponderación de Alexy es una fórmula hueca, que no añade nada al acto mismo de pesar o de comprobar el juego relativo de dos magnitudes escalares, mostrándose incapaz de explicar por qué efectivamente un principio pesa más que otro. Y, ciertamente, si lo que se espera de ella es que resuelva el conflicto mediante la asignación de un peso propio o independiente a cada principio, el juego de la ponderación puede parecer decepcionante; la "cantidad" de lesión o de frustración de un principio (su peso) no es una magnitud autónoma, sino que depende de la satisfacción o cumplimiento del principio en pugna, y, a la inversa, el peso de este último está en función del grado de lesión de su opuesto. Pero creo que esto tampoco significa que sea una fórmula hueca, sino que no es una fórmula "infalible", al modo como pretenden serlo los tradicionales criterios de

${ }^{48}$ MORESO, J.J., "Alexy y la aritmética de la ponderación”, en CARBONELL, M., (Editor), $E l$ principio de proporcionalidad y la interpretación constitucional, Quito, Ecuador, Ministerio de Justicia y Derechos Humanos, 2008, pp. 73-76. 
Revista Eletrônica de Direito Processual - REDP.

Rio de Janeiro. Ano 10. Volume 17. Número 2. Julho a Dezembro de 2016

Periódico Semestral da Pós-Graduação Stricto Sensu em Direito Processual da UERJ

Patrono: José Carlos Barbosa Moreira. ISSN 1982-7636. pp. 487-514

www.redp.uerj.br

resolución de antinomias; o mejor dicho, que no es una

fórmula en ningún sentido, sino un camino para alcanzarla, un camino que no sería preciso recorrer si contáramos con normas de segundo grado que nos indicasen el peso de cada razón y, con ello, la forma de resolver el conflicto ${ }^{49}$.

Alexy, intentando dar cumplida respuesta a las diversas objeciones que le se han formulado, señala:

Hay tres problemas básicos: el de la estructura, el de la racionalidad y el de la legitimidad. Entre estos problemas existen vínculos estrechos. La legitimidad de la ponderación en el derecho depende de su racionalidad. Cuanto más racional sea la ponderación, más legitima será la práctica de ponderaciones. Ahora bien, la estructura de la ponderación es decisiva para su racionalidad. Si los análisis revelaran que la ponderación no puede ser sino una decisión arbitraria, entonces sería cuestionable su racionalidad, así como su legitimidad en la jurisprudencia, sobre todo en la jurisprudencia constitucional. El problema de la estructura de la ponderación es, por tanto, el problema central de la ponderación en el derecho ${ }^{50}$.

La ley de la ponderación, siguiendo a Alexy, permite reconocer que la ponderación puede dividirse en tres pasos. En el primer paso es preciso definir el grado de la no satisfacción o de afectación de uno de los principios. Luego, en un segundo paso, se define la importancia de la satisfacción del principio que juega en sentido contrario. Finalmente, en un tercer paso, debe definirse si la importancia de la satisfacción del principio contrario justifica la restricción.

\footnotetext{
${ }^{49}$ PRIETO SANCHÍS, L., "El juicio de ponderación constitucional”, en CARBONELL, M., (Editor), El principio de proporcionalidad y la interpretación constitucional, Quito, Ecuador, Ministerio de Justicia y Derechos Humanos, 2008, p.101.

50 ALEXY, R., "La fórmula del peso", en CARBONELL, M., (Editor), El principio de proporcionalidad y la interpretación constitucional, Quito, Ecuador, Ministerio de Justicia y Derechos Humanos, 2008, pp.13-14.
} 
Esta estructura elemental muestra que debe rebatirse a los escépticos radicales de la ponderación, como por ejemplo Habermas o Schlink, cuando afirman que la ponderación, "para la que hacen faltan criterios racionales", se lleva a cabo “de manera arbitraria o irreflexiva, según estándares y jerarquías a los que se está acostumbrado" o cuando dicen que "en el examen de proporcionalidad en sentido estricto en definitiva [...se hace valer] sólo la subjetividad del juez" y que "las operaciones de valoración y ponderación del examen de proporcionalidad en sentido estricto [...] en definitiva sólo pueden llevarse a cabo mediante el decisionismo" o la no satisfacción del otro ${ }^{51}$.

\section{A Modo de Conclusiones}

La discrecionalidad judicial ha sido el tema dominante de la filosofía del derecho en las últimas décadas, sobre todo el impacto que causó el ataque de Dworkin, al positivismo, el cual tenía como uno de sus supuestos fundamentales el compromiso con la teoría de la discrecionalidad judicial (fuerte) como una posible explicación para la resolución de casos difíciles, frontalmente distanciada. A partir de ahí, se ha producido unos debates doctrinales intensos (Hart-Dworkin) en los que la teoría de Alexy, tanto sobre los derechos fundamentales como sobre la argumentación jurídica, añadía nuevos elementos.

La teoría de Alexy puede situarse, en cierta manera, ante los casos difíciles" (siguiendo la terminología hartiana) relativos a los derechos fundamentales. El interrogante que se plantea es qué hacer en aquellos casos en los que se presenta un conflicto de derechos fundamentales y el aplicador de la ley (el juez) debe dictar una sentencia. Es por ello, por lo que como primera conclusión, entendemos que la teoría de la ponderación de Alexy no se puede entender adecuadamente si se aleja del debate de la discrecionalidad judicial. Y aquí habrá que tomar en consideración las diversas

${ }^{51}$ Alexy, R., Ibidem. 
Revista Eletrônica de Direito Processual - REDP.

Rio de Janeiro. Ano 10. Volume 17. Número 2. Julho a Dezembro de 2016

Periódico Semestral da Pós-Graduação Stricto Sensu em Direito Processual da UERJ

Patrono: José Carlos Barbosa Moreira. ISSN 1982-7636. pp. 487-514

www.redp.uerj.br

posturas enfrentadas. Por una parte, la de quienes consideran que la discrecionalidad

es el modo cierto de razonamiento judicial a casos difíciles, no como un mal necesario, sino como un medio para lograr flexibilidad y racionalidad, recurriendo al sentido de justicia, cuando hay desacuerdo acerca de lo que el derecho exige en ciertas circunstancias. Por otro lado, la de quienes sustentan que la teoría de la discrecionalidad judicial no hace más que amparar un decisionismo y arbitrariedad judicial.

La teoría de la ponderación de Alexy goza de gran aceptación tanto en el ámbito doctrinal como jurisprudencial. Sin embargo, como hemos puesto de manifiesto, también es objeto de algunas críticas. Pero tal vez haya que poner de manifiesto que, precisamente, quienes hacen flaco favor a la teoría alexyana del principio de proporcionalidad sean todas aquellas sentencias, dictadas por jueces y magistrados que, invocando los principios de interpretación constitucional, de la ponderación, del principio de razonabilidad y tantos otros, sin embargo dicen aplicar la ley de la ponderación pero no siguen los tres pasos que Alexy recomienda. Es decir, no se menciona expresamente la adopción de una doctrina o de un criterio racional para justificar la conclusión adoptada en la decisión, puesto que no aparece en ninguna de las sentencias la referencia a una metodología para realizar la delimitación del derecho fundamental. Las decisiones judiciales que dicen aplicar el principio de ponderación, deberían explicar con nitidez cómo aplican esos tres pasos, deberían explicar la racionalidad utilizada para llegar a la sentencia que vayan a dictar. Estructura, racionalidad y legitimidad de la ponderación son imprescindibles para evitar caer en la arbitrariedad, en el mero decisionismo encubierto de un buenismo principiológico. De esa forma, se evitarían las críticas que atribuyen a la ponderación una mera retórica encubridora del criterio de un magistrado, a modo de juicio salomónico sin más.

\section{REFERENCIAS BIBLIOGRÁFICAS}

ALEXY, R., "Entrevista a Robert Alexy", trad. de M. Atienza, Doxa, 21, Alicante, 2001, pp.670-687. 
Revista Eletrônica de Direito Processual - REDP.

Rio de Janeiro. Ano 10. Volume 17. Número 2. Julho a Dezembro de 2016

Periódico Semestral da Pós-Graduação Stricto Sensu em Direito Processual da UERJ

Patrono: José Carlos Barbosa Moreira. ISSN 1982-7636. pp. 487-514

www.redp.uerj.br

ALEXY, R.,”Epílogo a la Teoría de los derechos fundamentales”, trad. de C. Bernal,

Revista Española de Derecho Constitucional, 22, nº 66, 2002.

ALEXY, R., Tres escritos sobre los derechos fundamentales y la teoría de los principios, Bogotá (Colombia), 2003.

ALEXY, R., Teoría de la argumentación jurídica: La teoría del discurso racional como teoría de la fundamentación jurídica, Madrid, Centro de Estudios Políticos y Constitucionales, 2008.

ALEXY, R., Teoría de los Derechos fundamentales, Madrid, Centro de Estudios Políticos y Constitucionales, 2008.

ALEXY, R., "La fórmula del peso", en CARBONELL, M., (Editor), El principio de proporcionalidad y la interpretación constitucional, Quito, Ecuador, Ministerio de Justicia y Derechos Humanos, 2008.

ALEXY, R., A theory of legal argumentation. The theory of rational discourse as theory of legal justification, Oxford, Oxford University Press, 2010.

ATIENZA, M., "Para una razonable definición de `razonable"', Doxa. Cuadernos de Filosofía del Derecho, núm. 4, Alicante, 1987, pp. 189 y ss.

ATIENZA, M., Tras la justicia. Una introducción al Derecho y al razonamiento jurídico, Ariel, Barcelona, 1993.

AZIZ CRETTON, R., Os princípios da proporcionalidade e da razoabilidade e sua aplicação no Direito Tributário. Rio de Janeiro, Lumen Iuris, 2001.

BARROSO, L. R.; BARCELlOS; A.P. (de), "O começo da historia. A Nova Interpretação Constitucional e o Papel dos Princípios no Direito Brasileiro" en Revista da EMERJ, v. 6, n. 23, 2003, pp.25-65. Disponible en. < www.emerj.tjrj.jus.br/revistaemerj_online/.../revista23_25.pdf >. (Acceso el 28.09.2016).

BERNAL PULIDO, C., "La racionalidad de la ponderación”, en CARBONELL, M., (Editor), El principio de proporcionalidad y la interpretación constitucional, Quito, Ecuador, Ministerio de Justicia y Derechos Humanos, 2008.

COMANDUCCI, P. "Formas de (neo)constitucionalismo: un análisis metateórico" en Miguel Carbonell Sánchez ( coord. ), Neoconstitucionalismo(s), Madrid, Trotta, 2003, pp.75-98.

DE LUCAS, J; VIDAL, E., "Una nota sobre interpretación constitucional en materia de derechos fundamentales", en VV.AA., Diez años de régimen constitucional (E. Álvarez Conde, ed.), Tecnos, Madrid. 1989, pp. 15 y ss.; 
Revista Eletrônica de Direito Processual - REDP.

Rio de Janeiro. Ano 10. Volume 17. Número 2. Julho a Dezembro de 2016

Periódico Semestral da Pós-Graduação Stricto Sensu em Direito Processual da UERJ

Patrono: José Carlos Barbosa Moreira. ISSN 1982-7636. pp. 487-514

www.redp.uerj.br

DE LUCAS, J;"Razonabilidad e interpretación constitucional: a propósito de una jurisprudencia reciente", en Introducción a los derechos fundamentales, vol. III, Servicio de Publicaciones del Ministerio de Justicia, Madrid, 1989.

FERRAJOLI, L. Democracia y Garantismo, Ed. de M. Carbonell, Trotta, Madrid, 2008 .

FERRAJOLI, L., Principia juris. Teoria del diritto e della democrazia. Vol. 2: Teoria della democracia, Roma, Laterza, 2007.

GARCÍA AMADO, J.A., El juicio de ponderación y sus partes. Crítica de su escasa relevancia, cit., p.1. www.geocities.ws/jagamado/pdfs/PONDERACION.pdf (acceso el 23.02.2014).

GARCÍA AMADO, J. A., "El juicio de ponderación y sus partes. Una crítica" en ALEXY, R., "Derechos sociales y ponderación”, GARCÍA MANRIQUE, Ricardo (ed.), Madrid, Fundación Coloquio Jurídico Europeo, 2007.

GARCÍA AMADO, J.A., El juicio de ponderación y sus partes. Crítica de su escasa relevancia, p.1. www.geocities.ws/jagamado/pdfs/PONDERACION.pdf (acceso el 23.02.2014).

GARZÓN VALDÉS, E., "Algo más acerca del "coto vedado"” en DOXA. Revista de Filosofía jurídica, Alicante, pp. 209-213. Disponible en: <doxa.ua.es/article/view/1989-n6-algo-mas-acerca-del-coto-vedado/pdf> (Acceso el 28.09.2016).

GUERRA FILHO, Willis Santiago, "Sobre os princípios constitucionais gerais: isonomia e proporcionalidade", en Revista dos Tribunais, nº719, sept., Sâo Paolo, 1995.

GUERRA FILHO, W.S., Processo Constitucional e Direitos Fundamentais. Instituto Brasilero de Direito Constitucional, Cesar Bastos Editor, 1999.

GUERRA FILHO, W.S., Teoría Processual da Constituiçâo. $2^{\mathrm{a}}$ ed., Sâo Paolo, Instituto Brasilero de Direito Constitucional, 2002.

HABERMAS, J., Facticidad y Validez. Sobre el derecho y el Estado democrático de derecho en términos de teoría del discurso. Trad. de Manuel Jiménez Redondo, Madrid, Trotta 1998.

LÓPEZ SÁNCHEZ, R., "El principio de proporcionalidad como criterio hermenéutico en la justicia constitucional", en Cuadernos Electrónicos de Filosofía del Derecho, n.23, 2011 
Revista Eletrônica de Direito Processual - REDP.

Rio de Janeiro. Ano 10. Volume 17. Número 2. Julho a Dezembro de 2016

Periódico Semestral da Pós-Graduação Stricto Sensu em Direito Processual da UERJ

Patrono: José Carlos Barbosa Moreira. ISSN 1982-7636. pp. 487-514

wWw.redp.uerj.br

MARTÍNEZ ZORRILLA, D., Conflictos constitucionales, ponderación e indeterminación normativa, Madrid, Marcial Pons, 2007, p. 161.

MORESO, J.J., “Alexy y la aritmética de la ponderación”, en CARBONELL, M.,

(Editor), El principio de proporcionalidad y la interpretación constitucional, Quito,

Ecuador, Ministerio de Justicia y Derechos Humanos, 2008.

MORESO, J.J., "Conflictos entre principios constitucionales" en Miguel Carbonell

Sánchez (coord.), Neoconstitucionalismo(s), Madrid, Trotta, 2003:

Neoconstitucionalismo(s), cit., pp.99-122.

PRIETO SANCHÍS, L., "El juicio de ponderación constitucional”, en CARBONELL,

M., (Editor), El principio de proporcionalidad y la interpretación constitucional, Quito, Ecuador, Ministerio de Justicia y Derechos Humanos, 2008.

SIQUEIRA CASTRO, C. R. de, O devido processo legal e a razoabilidade das leis na nova Constituição do Brasil. Rio de Janeiro, Forense, 1989.

SLAIBI FILHO, N., "Hermenêutica Constitucional”, Revista da EMERJ, nº 16. Rio de Janeiro, 2001. 